\title{
Comparative whole plastome and low copy number phylogenetics of the core Saccharinae and Sorghinae.
}

\section{Short title: COMPARATIVE PYLOGENETICS OF THE CORE SACCHARINAE}

Dyfed Lloyd Evans ${ }^{1,2, \dagger}$, Ben Hughes ${ }^{2}$ and Shailesh Vinay Joshi ${ }^{1,3}$

${ }^{1}$ South African Sugarcane Research Institute, 170 Flanders Drive, Private Bag X02, Mount

Edgecombe, Durban, 4300, South Africa

${ }^{2}$ BeauSci Ltd., Waterbeach, Cambridge, CB25 9TL

${ }^{3}$ School of Life Sciences, College of Agriculture, Engineering and Science, University of Kwa-Zulu

Natal, Private Bag X54001, Durban, 4000, South Africa

${ }^{\dagger}$ Corresponding author. Email: dyfed.sa@gmail.com Tel: 0027315087442. 


\section{Abstract}

Despite over 60 years’ worth of taxonomic efforts, the relationships between sugarcane (Saccharum hybrid cultivars), Sorghum and their closest evolutionary relatives remain largely unresolved. Even relationships between generally accepted genera such as Miscanthus and Saccharum have not been examined in any large-scale molecular detail. Genera such as Erianthus, Miscanthidium and Narenga pose even greater taxonomic contention. Erianthus is not monophyletic and Erianthus sect. Ripidium (Valdés and Scholz 2006, Lloyd Evans et al. 2019a; Welker et al. 2019) represents a distinct and separate genus, Tripidium Scholz. Miscanthidium is placed within Miscanthus by many workers, whilst the New World Erianthus species and Narenga are currently placed within Saccharum. As these species represent a significant portion of the gene pool that sugarcane breeders use for introgression into sugarcane, their taxonomic placement and relationships to Saccharum are of significant economic import. Erianthus species from the Americas have not been significantly employed in sugarcane breeding and may represent an untapped genetic resource. In an attempt to resolve the taxonomic relationships of these genera, we have assembled three novel chloroplasts, from Miscanthidium capense, Miscanthidium junceum and Narenga porphyrocoma (this latter assembled from transcriptomic and long read data). In parallel, five low copy number loci have been assembled from species within Saccharum, Miscanthus, Sarga and Sorghum. Phylogenetic analyses were performed using both low copy number genes and whole chloroplasts. The phylogenetic results were compared with karyotype data to circumscribe the genera most closely related to sugarcane. We reveal that genera Miscanthus and Saccharum are monophyletic and have never undergone polyploidization outside their own genera. Genera Erianthus, Miscanthidium and Narenga are allopolyploids, which excludes them from being members of Saccharum and Miscanthus. Moreover, all three of these genera have divergent evolutionary histories. We therefore support the use of the genera Miscanthus, Miscanthidium, Erianthus (for the New World Species) and Narenga for those 

made available under aCC-BY-NC-ND 4.0 International license.

species and genera most closely allied to Saccharum. Our data demonstrate that all these

genera should be excluded from Saccharum sensu lato.

Keywords: saccharinae, Saccharum complex, narenga, taxonomy, phylogenetics, plastome, low copy number 
Sugarcane (complex hybrids of Saccharum cultum Lloyd Evans and Joshi,

Saccharum officinarum L. and Saccharum spontaneum L. [Lloyd Evans and Joshi (2016)]) ranks amongst the top-ten crop species worldwide. Sugarcane also provides between 60 and $70 \%$ of total world sugar output and is a major source of bioethanol (Reddy et al. 2008). Saccharum officinarum is the type species for genus Saccharum L. Saccharum sensu stricto (s.s.) consists of four true members of genus saccharum: Saccharum spontaneum, Saccharum robustum, Saccharum officinarum and Saccharum cultum (Lloyd Evans and Joshi, 2016). However, many authorities also treat Saccharum in a broader sense (Saccharum sensu lato). For example, Kew’s GrassBase currently recognizes 36 species within Saccharum (http://www.kew.org/data/grasses-db/sppindex.htm\#S).

Mukherjee (1957) first defined the 'saccharum complex' as group of potentially interbreeding genera believed to be involved in the origins of modern sugarcane hybrids (Saccharum $\times$ officinarum/Saccharum $\times$ cultum [Lloyd Evans and Joshi (2016)]). This concept was further refined by Clayton and Renvoize (1986) who extended the subtribe Saccharinae to include the genera: Erianthus Michaux, Eriochrysis P. Beauv., Eulalia Knuth, Eulaliopsis Honda, Homozeugos Stapf, Imperata Crillo, Lophopogon Hack, Microstegium Nees, Miscanthus Andersson, Pogonatherum P. Beauv., Polliniopsis Hayata, Polytrias Hack, Saccharum and Spodiopogon Trin. (as a result many of these genera have been re-classified as Saccharum and genus Saccharum now comprises between 35 and 40 species, mostly from the tropics and sub-tropics). The suggestion being, that all these genera are closely allied to Saccharum and were actually involved in the evolution of sugarcane's ancestors. This paper has had considerable taxonomic influence and, for example, both the New World and Old World gernera of Erianthus as well as Narenga porphyrocoma are now all included within Saccharum sensu lato.

However, some authorities have considered Erianthus as a distinct genus (containing 28 species) originating in the Americas, Africa, Europe and Asia (Mukherjee, 
1958; Molina, 1981; Watson and Dallwitz, 1992). Morphologically, Erianthus is

distinguished from Saccharum by the presence of awned spikelets in the former and awnless spikelets in the latter (Mukherjee, 1958). However, the Old World species of Erianthus are grouped in a different section (Erianthus sect. Ripidium (Trin.) Henrard) or a distinct genus (Tripidium H. Scholz) by various authors (Grassl, 1972; Besse et al., 1997; Hodkinson et al., 2002; Valdés and Scholz, 2006). Narenga Bor and Miscanthidium Stapf. are also accepted as distinct genera by a few authors (e.g., Clayton, 1972; Watson and Dallwitz, 1992; Hodkinson et al. 2013) rather than including their species in Saccharum (Tripidium) or Miscanthus (Miscanthidium).

The circumscription of Saccharum remains highly controversial and has changed significantly over the past century. Several phenetic studies have indicated strong molecular differentiation between Saccharum and Erianthus (Besse et al., 1998; Nair et al., 2005; Selvi et al., 2006). Conversely, a phylogenetic analysis based on the internal transcribed spacer (ITS) of the nuclear ribosomal DNA (Hodkinson et al., 2002) found no support for this division, even though this study suggested that Saccharum s.l. is polyphyletic. Even the taxonomic delimitation between Saccharum and Miscanthus is not clear, with intergeneric hybrids occurring between them (Clayton and Renvoize, 1986; Hodkinson et al., 2002). However, a recent paper (Lloyd Evans and Joshi, 2016) comparing whole plastid genomes revealed a clear phylogenetic separation of Miscanthus and Saccharum, with the genera diverging at least 3.4 million years ago.

Previous studies (Estep et al. 2014, Welker et al. 2015) using low copy number genes and Soreng et al. (2015) using whole chloroplast analyses, demonstrated that the subtribe Saccharinae Griseb. was not monophyletic. However, both these studies had incomplete samplings of Saccharum s.s., as well as sugarcane’s known close relatives (Miscanthus, Miscanthidium). 
As the Saccharum complex/Saccharinae comprises the gene pool that sugarcane breeders use when attempting to introgress useful characteristics into sugarcane the true relationship of these genera and species to each other, as determined by molecular techniques is of considerable import and relevance. This is especially the case, as modern molecular techniques do not support the concept of a 'saccharum complex’ (D’Hont et al. 2008). Moreover, there is increasing evidence that Saccharum is a well-defined lineage that diverged over a long evolutionary period from the lineages leading to the New World Erianthus and Old World Miscanthus genera (Grivet et al. 2004; Welker et al. 2015; Lloyd Evans and Joshi, 2016).

The recent finding (Shi et al. 2016) that plant chloroplasts are completely transcribed means that it is theoretically possible to assemble whole plant chloroplasts from transcriptomic data. This means that we can begin to fill in the gaps in assembled Saccharinae chloroplast data by mining transcriptomic datasets.

One of the problem species within Saccharum has always been Saccharum narenga (Nees ex Steud.) Wall. ex Hack. In 1940 Bor moved the species from Saccharum into Narenga as Narenga porphyrocoma (Hance ex Trimen) Bor (based on the basionym Eriochrysis narenga Nees ex Steud.). Bor excluded this species from genus Saccharum due to its possession of the following anomalous characters: non-coriaceous glumes, the absence of non-flowering stems, the plant generally being less 'robust', a reduced panicle, the presence of secondary branches only on the lowest lateral branches of the panicle and the presence of a fourth glume in the florets (Janaki-Ammal, 1942). To add to the confusion, the NCBI's taxonomy (https://www.ncbi.nlm.nih.gov/taxonomy/?term=saccharum\%20narenga) defines this species as Narenga porphyrocoma, whilst Kew’s GrassBase defines it as Saccharum narenga (http://www.kew.org/data/grasses-db/www/imp09051.htm). Tropicos also defines the accepted name as Saccharum narenga (http://www.tropicos.org/Name/25509769? tab=acceptednames). 
Though Saccharum narenga (Narenga porphyrocoma) has not been used extensively in sugarcane introgression breeding, it does possess a number of characters that would be beneficial to sugarcane: broad-range disease resistance, pest resistance, root pest resistance, drought resistance and waterlogging resistance, early flowering and high tillering (Heinz, 2015; Shrivastva and Srivastva 2016).

Saccharum narenga has a natural range that extends from India through Burma and Thailand to south-eastern China and Taiwan, with a rump population in subtropical Ethiopia (Clayton et al. 2006). It is classed as 'potentially weedy' (Cheavegatti-Gianotto et al. 2011). As such, its taxonomic relationships to Saccharum s.s. is of great import as it could be a bridge species, allowing transgenes to escape from sugarcane into the wild.

Following Estep et al. (2015) we have assembled five low copy number gene regions (Aberrant panicle organization1 (apo1), Dwarf8 (d8), two exons (7 and 8) of Erect panicle 2 (ep2), and Retarded palea 1 (rep1)) from four Miscanthus accessions, one Miscanthidium accession and four Saccharum accessions along with Sorghum propinquum (Kunth) Hitchc. and Sarga versicolor (Andersson) Spangler. In addition, the chloroplast genome of Saccharum narenga was assembled from high depth transcriptomic data.

Comparison of plastome and low copy number genomic data indicate that Old World Erianthus species and Miscanthidium species are hybrids of a common ancestral lineage, sister to both Saccharum and Miscanthus with an early-diverging species that is sister to all the crown Saccharum species. Saccharum narenga has the same ancestry, but about three million years ago it underwent a back-hybridization with a different early-diverging Saccharum sister. The lineages leading to Miscanthus sinensis Andersson and Miscanthus sacchariflorus (Maxim.) Benth. \& Hook. f. ex Franch. reciprocally hybridized with each other, leading to a duplication in the base genome. Saccharum emerges as being unusual in the entire grouping, not having undergone any ancestral hybridizations outside its own genus 
subsequent to divergence from Miscanthus.

We conclude that Saccharum, Erianthus, Miscanthidium, Miscanthus, Tripidium (Erianthus sect. Ripidium) and Narenga are separate genera with distinct evolutionary histories. However, an ancestral member of Saccharum was involved in the origins of Erianthus and Miscanthidium. Both chloroplast and genomic data supports inclusion of genus Sarga within the saccharinae subtribe, but more studies are required to ascertain the placement of Sorghum. Though Narenga porphyrocoma is genetically closer to Saccharum (at both the plastome and gross genomic level) than any of the other genera it should be excluded from genus Saccharum on the basis of different physical characteristics, different evolutionary ancestry and different base chromosomal counts. 


\section{MATERIALS AND METHODS}

\section{Plant Materials and Transcript/Chloroplast Extraction}

Leaf material for Saccharum narenga (Narenga porphyrocoma) was collected in Malaysia (isolatedd to the north of Kak Bukit), voucher Mah:CSS:013. Chloroplasts were captured with conserved tRNA magnetic bead bound primers and sequenced with ONT MinION as described previously (Lloyd Evans et al. 2019b).

\section{Low Copy Number Locus Assembly}

Low copy number regions were assembled for the following genes: Aberrant panicle organization1 (apo1), Dwarf8 (d8), two exons (7 and 8) of Erect panicle 2 (ep2), and Retarded palea 1 (rep1). We assembled these regions from the following GenBank sequence read archive (SRA) accessions: Sorghum propinquum (SRR072055); Sarga versicolor (SRR427176); Miscanthidium junceum (SRR396848 and SRR396849); Miscanthus sacchariflorus var. Hercules (SRR486748); Miscanthus x giganteus (SRR407328 and SRR407325); Miscanthus transmorrisonensis (SRR396850); Saccharum hybrid LCP85-385 (SRR427145); Saccharum hybrid RB72454 (SRR922219) and Saccharum spontaneum SES234B (SRR486146). Narenga porphyrocoma transcripts were assembled based on the Miscanthidium junceum assemblies using the SRA accessions

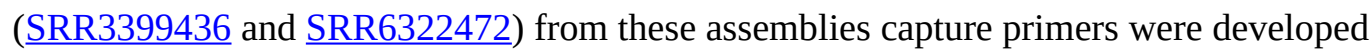
(Supplementary Appendix 1) and these were employed for magnetic bead capture and MinION sequencing (Lloyd Evans 2021). Miscanthus sinensis cv. Andante genomic reads were kindly donated by CSS, Waterbeach, Cambridge, UK. Gene loci were assembled as described previously (Lloyd Evans and Joshi, 2017) using the closest orthologue for each gene for Mirabaiting and SPAdes for assembly. Where a second copy of the gene co-assembled (typically as a shorter, second, assembly contig), this was co-assembled along with the primary gene copy. In Miscanthus, M. sinense was used to bait the A copy and M. sacchariflorus was used to bait the B copy for each species. For Saccharum, Saccharum spontaneum was used to bait the spontaneum copies of the gene from Saccharum hybrid 
LCP85-385. In addition, all species that were near neighbours of sugarcane were used to bait data from Saccharum hybrid LCP85-385 to ensure that no alternate copies of any gene were present in the genome. All Miscanthus sinense cv Andante assemblies were have been deposited in EMBL/GenBank under the project identifier PRJEB22229 and Narenga chlroplast assemblies were deposited in project ????????. Finally, Narenga transcript sequences were deposited in project ?????. All other gene assemblies were deposited in the Dryad repository along with their optimized alignment (DOI available upon acceptance).

\section{Chloroplast Assembly.}

The Miscanthidium junceum chloroplast was assembled from SRA datasets: SRR396848 and SRR396849, as described previously (Lloyd Evans and Joshi 2016) using Saccharum spontaneum and Miscanthus sinensis assemblies for baiting. The Miscanthus x giganteus plastome sequence was assembled from the SRA datasets SRR407328 and SRR407325 and the Sarga versicolor chloroplast was assembled from the SRA accession SRR427176, using the same methodology. The Miscanthidium capense Joshi1 chloroplast genome was assembled using 13 novel PCR primers (detailed in supplementary Appendix 2). Leaf samples were derived from a plant at the South African Sugarcane Research Institute living collection, Durban. Illumina short reads were derived from the PCR products and were assembled using SPAdes, as described previously (Lloyd Evans and Joshi, 2016) using the Miscanthidium junceum chloroplast as a reference.

The Microstegium vimineum chloroplast was assembled using a blend of RNAseq data (NCBI SRA accession: ERR2040772) and previously assembled Microstegium vimineum chloroplast fragments (isolated from the NCBI using the query: "Microstegium vimineum”[organism] and (chloroplast or plastid)). The chloroplast fragments were converted to FASTQ with a custom PERL script. Reads corresponding to the chloroplast were isolated using mirabait with a k-mer of 27 employing the Rottboellia cochinchinensis and 
Sorghastrum nutans chloroplasts as a reference. All reads were co-assembled with SPAdes, using the Rottboellia cochinchinensis chloroplast as an untrusted reference. Eight contigs were obtained, which were scaffolded on the Rottboellia cochinchinensis chloroplast. Sequences corresponding to the gap regions (the largest of which was the entire IRa region) were excised from the Rottboellia cochinchinensis chloroplast and were surrounded by $1 \mathrm{kbp}$ regions from the Microstegium vimineum assembly. These isolated regions were baited against the read pool with mirabait and a k-mer of 25 before being assembled with SPAdes and stitched into the Microstegium vimineum assembly. After assembling and filling the gaps, followed by a second round of assembly to fill the remaining three small sequence gaps, the complete chloroplast sequence of Microstegium viminium was obtaind. The EMBL annotated version of the assembly can be downloaded from the Dryad digital repository.

Our previously assembled and annotated transcriptomic assembly of Narenga porphyrocoma (available from the Dryad digital repository) was also utilized in this study.

\section{Gene Region Alignments}

Gene regions assembled in this study were merged with the equivalent gene regions from a subset of the data from Welker et al. 2015. All regions were aligned independently using SATÉ, with MAFFT as the aligner and Muscle as the sub-alignment joiner. Alignments were adjusted manually and trimmed. Each individual alignment was input into RAxML and a phylogenetic analysis (100 replicates) was run to identify the most likely tree. If alternate copies of genes were in the same position in the phylogeny these were linked. Genes were stitched together with a custom Perl script. If the positions of genes were uncertain, all alternate positions were generated. The phylogeny was run with RAxML and the sub-alignment giving the strongest phylogenetic signal was chosen. Using this methodology, we generated the optimal alignment (available from the Dryad repository). Chloroplast genomes were aligned, as previously described (Lloyd Evans and 
Joshi, 2016). A list of all chloroplasts used in the alignment, including GenBank accessions, voucher accession and publications are given in supplementary Appendix 3.

\section{Phylogenetic Analyses}

The gene alignment was divided into the five constituent gene regions and models of DNA evolution were determined using PartitionFinder (Lanfear et al. 2014) and the AICc criterion. For each partition, the GTR $+\Gamma$ model was chosen. To determine the best topology, two independent runs of RAxML RAxML (version 8.1.17) (Stamakis, 2006), using different seeds were run, with 100 replicates. Both runs yielded the same best tree topology and this was used as the reference for all future analyses. Concatenated trees were reconstructed using both maximum likelihood (ML) and Bayesian approaches and rooted at Arthraxon. The ML tree was estimated with RAxML using the GTR $+\Gamma$ model for all 5 partitions, and 6000 bootstrap replicates. The Bayesian tree was estimated using MrBayes v.3.2.1 (Ronquist and Huelsenbeck 2003) using a gamma model with six discrete categories and partitions unlinked. Two independent runs with 25 million generations each (each with four chains, three heated and one cold) were sampled every 1,000 generations. Convergence of the separate runs was verified using AWTY (Nylander et al. 2008). The first six million generations were discarded as burn-in. The ML trees and the MB trees were mapped onto the best topology from the initial RAxML run with SumTrees.

For the whole chloroplast alignment, the alignment was divided into LSC, IRA, SSC and IRB partitions. The GTR $+\Gamma$ partition was chosen for all partitions. Maximum likelihood and Mr Bayes runs were executed as described above for the low copy number gene data.

Divergence times on the whole chloroplast alignment were estimated using BEAST 2.4.4 (Drummond et al. 2012), on a 24-core server running Fedora 25, using four unlinked 
partitions (as above). The concatenated analysis was run for 50 million generations sampling every 1,000 under the GTR $+\Gamma$ model with six gamma categories. The tree prior used the birth-death with incomplete sampling model (Drummond et al. 2012), with the starting tree being estimated using unweighted pair group method with arithmetic mean (UPGMA). The site model followed an uncorrelated lognormal relaxed clock (Drummond et al. 2006). The analysis was rooted to Arundinella, with the age of Zea mays divergence estimated as a normal distribution describing an age of $13.8 \pm 2$ million y (Estep et al. 2014). Convergence statistics were estimated using Tracer v.1.5 (Rambaut et al. 2013) after a burn-in of 15,000 sampled generations. Chain convergence was estimated to have been met when the effective sample size was greater than 200 for all statistics. Ultimately, 30,000 trees were used in SumTrees to produce the support values on the most likely tree (as determined above) and to determine the 95\% highest posterior density (HPD) for each node. All final trees were drawn using FigTree v.1.4.0 (tree.bio.ed.ac.uk/software/figtree/) prior to finishing in Adobe Illustrator. Final alignments and trees are available from TreeBase (TB2:S21154 and TB2:S21155).

\section{Karyotyping}

Images from the original publications (Sarga vrsicolor: Sun et al. (1994); Miscanthus sinensis: Cramiec-Głąbik et al. (2012); Miscanthidium capense: Strydom et al. (2000) and Hoshino and Davidse, (1988); Erianthus giganteus: Burner and Webster, (1994); Narenga porphyrocoma: Jagathesan and Sreenivasan (1967), Saccharum spontaneum: Ha et al. (1999); Saccharum officinarum: Li et al. (1959) and Divinagarcia and Ramirez, (1976)) were scanned in grayscale at 1200dpi prior to export as tiff files. Images were imported into Adobe Photoshop and were adjusted to improve contrast and sharpness. Images were reexported in TIFF format and imported into the image analysis toolkit, icy (http://icy.bioimageanalysis.org). The Painting plugin 
(http://icy.bioimageanalysis.org/plugin/Painting) was employed to create a mask around each chromosome, with centromere to P-arm and centromere to Q-arm lengths determined by icy's viewer pane tools. Three independent measurements were taken in each case and written to Excel files. A custom Perl script read in the file and determined chromosomal arm lengths, scaling the measurements based on the scale bar information from the original publications. The script output chromosome descriptor files in '.cfg' format which were used as input to coloredChromosomes.pl (Böhringer et al. 2002) using custom configuration files for each species. The outputs (PostScript files) were imported into Adobe illustrator for integration prior to export as a single PDF file. 


\section{RESULTS}

\section{Gene Assembly}

Genes and gene fragments were assembled using a bait and build process, as described previously (Lloyd Evans and Joshi, 2017). For our 11 novel species/accessions (see Materials and Methods for details), all genes and gene fragments were assembled, except for the following: apo1 — Miscanthus transmorrisonensis A, Miscanthus sacchariflorus A, Saccharum hybrid RB7234; d8 Saccharum hybrid RB7234, Sorghum propinquum, Miscanthus sacchariflorus B (partial); rep1: Saccharum hybrid RB7234. As a result, all species (including alternates) meet the $3 / 5$ sequences present chosen as a minimum cutoff for phylogenetic studies established by Estep et al. (2014). Sequencing and assembly of the Narenga porphyrocoma transcripts yielded 100\% identity with transcript based sequencing.

\section{Chloroplast Assembly}

The two Miscanthidium chloroplasts were assembled as described previously (Lloyd Evans and Joshi, 2016). The Miscanthidium junceum chloroplast was 141149 bp in length and the Miscanthidium capense chloroplast was 141213 bp long (both had the same gene content). The same methodology was employed in the assembly of the Miscanthus x giganteus (141 $220 \mathrm{bp}$ long) and Sarga versicolor (140 951 bp long) chloroplasts. These latter two chloroplast assemblies had the same gene contnt and gene organization as the two Miscanthidium assemblies. Images of the four chloroplast assemblies generated in this study are shown schematically in Figure 1. The RNA-seq based assembly of Narenga porphyrocoma was 141213 bp long.

\section{Narenga MinION Chloroplast Assembly}

The MinION data for Narenga porphyrocoma was assembled with Canu (Koren et al. 2017) and the assembly graph was analyzed with unicycler (Wick et al. 2017) this revealed two distinct isoforms with the difference between them being an inversion of the SSC (short single copy region) with the ratios of the canonical and reversed forms being 52\%:48\%. The MinION based 
assemblies and RNA-seq based assemblies were 141217 bp long, the lengh increased as compared with the transcript-based assembly due to a 4 bp insertion in the LSC. Apart from this, the sequences differed by 22 sequence alterations due to DNA to RNA transcription and 6 sequence alterations due to differing origins of the sequences.

\section{Low Copy Number Gene Phylogeny}

Low copy number gene evolution for the Andropogoneae has been extensively analyzed previously (Estep et al. 2014; Welker et al. 2015). Indeed, the backbone of our phylogeny (Fig. 2) is based on data generated by these studies. However, we extend these studies by providing additional data for Sarga versicolor, Miscanthus, Miscanthidium and Saccharum. This fills in the gaps in the previous studies. The sister relationship of Sarga and Saccharum s.l. is well supported (85\% ML, 1 BI) and monophyly of Saccharum s.s. is $100 \%$ supported. There is an early split between the 'B' genomes of Miscanthidium and Erianthus and this clade is also $100 \%$ supported. The next split is between a clade formed of Pseudosorghum fasiculaire and Miscanthus and the 'A' genomes of Miscanthus, Erianthus, Narenga and Saccharum. This split has poor ML support (62\%) but good MB support (0.94) — allied with the short internal branches this is probably a sign of rapid radiation. The sister relationship of Pseudosorghum and Miscanthus has good support (83\% ML, 0.9 MB) and monophyly of Miscanthus (as well as the split between the A and B genomes of Miscanthus) has 100\% support. The split between the 'A' genome of Miscanthidium/Erianthus and Saccharum s.s. has good support (79\% ML, 1 MB). In addition, the sister relationship of the Narenga 'B' genome and core Sacharum has decent support (65\% ML, 0.99 MB). Monophyly of core Saccharum is 100\% supported.

However, within Saccharum, branches have relatively poor support and the sister relationship of Saccharum officinarum and Saccharum spontaneum is not supported (this has 100\% support in the chloroplast phylogeny), indicating that the dataset may have insufficient characters to resolve the relationships between close sister species (this is confirmed by ongoing studies with nine low copy number regions, D. Lloyd Evans, personal communication).

\section{Chloroplast Phylogeny}


Chloroplast phylogeny, both phylogram (Figure 3) and chronogram (Figure 4) reveal that Tripidum (Erianthus sect Ripidium) is clearly distinct from Saccharum s.s. and Saccharum s.l. being 11.1 million years divergent. Sorghum and Sarga are sister to the core Saccharinae (6.6 million years divergent). Miscanthus diverged from Saccharum 3.7 Ma. Miscanthidium diverged from Saccharum 3 Ma and Narenga diverged from Saccharum 2.9 Ma. Within Saccharum we see the expected divergence of Saccharum spontaneum, Saccharum officinarum and the Sugarcane hybrid cultivars (based on Saccharum cultum). Sorghum is also clearly distinct from and 6.7 million years divergent from Sarga.

\section{Karyotype Analyses}

By mining historical data we have managed to generate integrated ideograms depicting the basal (x) chromosome complement for Sarga versicolor, Miscanthidium capense, Erianthus giganteus, Miscanthus sinensis, Narenga porphyrocoma, Saccharum spontaneum and Saccharum officinarum (Fig. 5). In the majority of cases, chromosomes were small (on the order of 2$3 \mu \mathrm{m}$ in length), with a few anomalies in Miscanthus sinensis, Saccharum officinarum and, most notably, Narenga porphyrocoma. In all cases lengthened chromosomes or chromosomes with satellites were compatible with chromosomal fusion events. In the majority of cases, changes in base chromosomal counts were compatible with allopolyploid hybridization events. 


\section{DISCUSSION}

We have assembled four new whole chloroplast genomes (Miscanthidium capense, Miscanthidium junceum, Miscanthus x giganteus, Narenga porphyrocoma and Sarga versicolor and we have assembled low copy number genomic loci from Sarga versicolor, Miscanthus saccharuflorus, Miscanthus x giganteus, Miscanthus transmorrisonensis and Miscanthus sinensis cv. Andante, Narenga porphyrocoma as well as Miscanthidium junceum, Saccharum hybrid LCP85-384, Saccharum spontaneum SES245A and Saccharum hybrid RB7234. These data have been integrated with previously published low copy number gene data (Fig. 2) and previously published chloroplast data (Fig. 3 and Fig. 4) to yield the most comprehensive analysis of the origins of Saccharum s.l. performed to date.

MinION sequencing of the Narenga porphyrocoma chloroplast yielded two isoforms with the SSC region inverted between them. Both isoforms were present at almost equal concentrations. This finding agrees with recent analyses of plant chloroplast and indicates that chloroplasts in plants exist as two isoforms (Walker et al. 2015; Turudić et al. 2021) (Fig. 6).

Both low copy number gene and whole chloroplast phylogenetics clearly reveal that genus Erianthus is not monophyletic, with the Old World Species (Erianthus sect. Ripidium) clearly being evolutionarily very divergent from Saccharum. This supports the placement of these former Erianthus species not within Saccharum, but within the genus Tripidium (the type species for which is Tripidium ravennae).

The New World Erianthus species (now placed within Saccharum and represented by Saccharum villosum, Saccharum asperum, Saccharum giganteum and Saccharum angustifolium) along with Miscanthidium are clearly allopolyploids, with an A and $\mathrm{B}$ genome. Comparison of the gene and chloroplast phylogenies reveals that the $\mathrm{A}$ genome (the female parent) was derived from a Saccharum s.s. ancestor. Miscanthidium and Erianthus are monophyletic and divergent from each other, though they share a common 
ancestry. Saccharum narenga has a different ancestry, sharing an A genome with

Miscanthidium, though its B genome derives from a more recent sister genome to Saccharum (which is supported by the chloroplast phylogeny).

Saccharum s.s. is monophyletic and shows no allopolyploidization outside its own genus (modern sugarcane hybrids are a complex of three genomes: Saccharum spontaneum, Saccharum officinarum and Saccharum cultum [Lloyd Evans and Joshi (2016)]). Though we could recover the Saccharum spontaneum copy of the low copy number genes within the Saccharum hybrid LCP85-384 genome; despite exhaustive gene assembly attempts we could not find any other divergent forms of the low copy number genes. This rather gives the lie to the 'saccharum complex' theory, demonstrating that sugarcane has not hybridized outside the boundaries of Saccharum s.s. and is not a melange of different progenitor species.

Miscanthus is also monophyletic and, again, shows no evidence of allopolyploidization outside its own genus. Pseudosorghum fasiculaire sits as an outgroup to Miscanthus, and its genome shows no evidence of secondary gene copies due to ancestral hybridization. As such, allopolyploidization within Miscanthus seems to have happened early in the evolutionary history of Miscanthus itself. It seems that the early lineages leading to Miscanthus sinensis and Miscanthus sacchariflorus hybridized reciprocally with each other, resulting in a chromosomal fusion event, and it was these hybrids that led to modern $M$. sinensis and M. sacchariflorus lineages.

The low copy number gene phylogeny indicates that the B genome of Miscanthidium and Erianthus diverged first. An ancestral form of this lineage hybridized with an early form of the 'A' genome lineage and it was this hybrid that led to Miscanthidium and Erianthus. Miscanthidium remained in Africa, whilst Erianthus species traversed Asia to reach the Americas by means of the Beringia land bridge (Zimov et al. 2012).

In Narenga, only two gene copies were found, one corresponding to the A genome and one that serves as an outgroup to Saccharum s.s. This was confirmed by 
transcript capture and MinION sequencing. The Sacharum s.s. outgroup being the female lineage, as demonstrated by the chloroplast phylogeny. We do not know from our data if Narenga started as a B-genome A-genome hybrid and was originally part of the Miscanthidium clade (but this seems likely).

Mapping chromosome numbers onto the divergence backbone (Fig. 7) we see that the majority of the lineages have different chromosome numbers. We start with Sarga $(n=5)$ which makes it likely that the A genome was also $n=5$. There was a genome duplication held in common between Miscanthus and Saccharum (Kim et al. 2014), so the common ancestor of both these lineages had $n=10$ chromosomes. We would expect (simplistically) that Miscanthidium and Erianthus would have $\mathrm{n}=5+\mathrm{n}=10$ (ie $\mathrm{n}=15$ ) as the base chromosome number. Indeed, studies show that the base chromosome numbers in both these groups is $\mathrm{n}=15$.

The base chromosome number in Pseudosorghum is 10, but in Miscanthus it's 19. We predict that there was a chromosome doubling in Miscanthus due to allopolyploidization between ancestral Miscanthus lineages, but two chromosomes fused, leading to $n=19$ as the base chromosome number (this leads to the satellite chromosome seen in M. sinensis chromosome 1 in Fig. 5). The base chromosome number in Saccharum is 10, though there were probably chromosomal fusions in $S$. spontaneum giving a base number of 8 (and yielding two long chromosomes). The outlier to this nice series is Narenga. If this genome started as a hybrid of A and B genomes, we would expect a base number of $n=15$. If it's genome derived only from the A genome then we would have a base number of $n=10$ (this evolutionary series is mapped schematically in Fig. 7).

Given that allopolyploidization took place in Narenga to an n=10 Saccharum s.s. ancestor, we would expect either $n=25$ or $n=20$ as base chromosomal numbers. But the base chromosome number in Narenga is $n=15$. How can these studies be reconciled? Part of the answer may come from karyotype analyses (Fig. 5). Miscanthidium capense and 
Saccharum giganteum (Erianthus giganteus), both with $\mathrm{n}=15$ have small chromosomes

(Hoshino and Davidse, 1988; Burner and Webster, 1994). However, Narenga has a mix of larger and smaller chromosomes, as well as a single chromosome with a clear satellite, indicating that some of the chromosomes resulted from chromosomal fusion. Thus, in Narenga, a combination of chromosome loss and fusion could have led to the reduction of $n=20$ or $n=25$ (probably the most likely) to $n=15$. As a result, base chromosome numbers in Sarga, Pseudosorghum, Miscanthus and Saccharum are different. Miscanthidium, Erianthus and Narenga have the same base chromosome numbers n=15, but Miscanthidium and Erianthus have small chromosomes whilst Narenga has a mix of short and long chromosomes. Moreover, Miscanthidium has a distribution in Africa, whilst Erianthus species are found throughout the Americas and probably reached the continent via Beringia, as did many other grass species (Zimov et al. 2012). Narenga represents a species with an Asian distribution (from India to China) but with a rump population in Africa (Ethiopia), indicating that this species might have arisen in Africa and colonized Asia via a land bridge at the base of Arabia during a global sea-level minimum (Bailey et al. 2007).

\section{Conclusion}

For the first time, we have assembled and annotated the complete chloroplast genome of two Miscanthidium species. Integrating our previous transcript-based assembly of the $N$. porphyrocoma chloroplast with the newly-assembled chloroplasts of Miscanthidium junceum , M. capense, Miscanthus x giganteus and Sarga timorense along with enriched low copy number datasets we present comprehensive phylogenies of the Saccharinae. We demonstrate that Miscanthidium and Erianthus (excluding Tripidium species) are monophyletic and separate from both Saccharum and Miscanthus (indeed, they are allopolyploid, whilst Miscanthus and Saccharum only show hybridization within their own genus). 
Miscanthidium and Erianthus are also monophyletic, though they are sister taxa. We therefore support the use of Miscanthidium for the African species Miscanthidium junceum (formerly Miscanthus junceus) and Miscanthidium capense (formerly Miscanthus capensis syn Miscanthus ecklonii). Erianthus contains the type species for Erianthus (Erianthus giganteus, syn Saccharum giganteum) and our data supports the use of Erianthus for this grouping, which is distinct from Saccharum in terms of evolutionary origin and chromosome numbers). Moving Miscanthus ecklonii from Miscanthus into Miscanthidium means that Miscanthus loses its type species. However, as Hitchcock also defined $M$. japonicus (Trin.) Andersson (basionym Saccharum floridulum Labillardière; described in 1824), which is synonymous with Miscanthus floridulus (Labil.) as a second type for Miscanthus, then M. floridulus now becomes the type species for Miscanthus s.s.

Narenga is much more difficult to place. It has the same basic chromosomal number as Erianthus and Miscanthidium, but a different chromosome length pattern. It is a hybrid of a species ancestral to Miscanthidium and Erianthus with a Saccharum ancestor (the rump population for this species in Ethiopia indicate it may have originated in Africa [http://www.kew.org/data/grasses-db/www/imp09051.htm]). Thus, it could be placed in Miscanthidium or in Saccharum (chloroplast analyses would indicate a placement in Saccharum). However, its different origins, chromosomal fusions in its ancestry, base chromosome number of 15 and physical characteristics place it outside Saccharum s.s. We therefore conclude that it should be within its own genus and that its preferred name should be Narenga porphyrocoma (Hance ex Trimen) Bor.

It should also be noted that, in terms of the Saccharum complex, which is an interbreeding population, Narenga porphyrocoma is the closest genus to Saccharum, followed by Miscanthidium and Erianthus, Pseudosorghum and Miscanthus. As only these species lie within the about 3.4 to 4.2 million year window for hybridization in the wild (Lloyd Evans and Joshi 2016), this represents the effective limit of the Saccharum complex. Within a 
broader sense, both gene and chloroplast phylogenies show that all the above genera should be included in the Saccharinae, along with Sarga. Gene-based phylogenies indicate that Microstegium, Sorghastrum and Polytrias might also be included in the Saccharinae. Chloroplast phylogeny indicates the inclusion of Sorghum, Imperata and Pogonatherum. However, gene-based and chloroplast based phylogenies disagree on the placement of Sorghum and Pogonatherum. We do not have equivalent samplings on the other taxa. As a result more work needs to be done to confirm the true extent of the Saccharinae, though we demonstrate that current definitions of both the Saccharum complex and the Saccharinae subtribe are too broad and require revision.

Our findings cast doubt on the validity of the 'Saccharum complex' as a group of interbreeding genera that led to the evolution of modern sugarcane. Indeed, we find no evidence for the introgression of any species outside Saccharum into the genome of sugarcane. Moreover, only four genera: Pseudosorghum, Miscanthus, Miscanthidium and Narenga lie within the 3.8 million year window in which wild hybridization is possible within the Saccharinae and thus these genera circumscribe the extent of the Saccharum complex. 


\section{FUNDING}

This work was funded by the South African Sugarcane Research Institute and Cambridge Sequence Services.

\section{Author Contributions}

DLIE and SVJ conceived the initial experiment, DLlE extended and amended the experiment design. SVJ provided the SASRI plant materials. DLIE designed PCR primers, performed the sequence assemblies, alignment and phylogenetics, developed all software scripts, analysed and interpreted the data and wrote the paper. $\mathrm{BH}$ captured and sequenced the Narenga porphyrocoma chloroplast and low copy number transcripts. SVJ and BH proofread the paper. All authors read and agreed to the final version of the manuscript.

\section{ACKNOWLEDGEMENTS}

We thank Mr E. Albertse for performing the DNA isolation, PCR amplifications and DNA extractions for Miscanthidium capense and Mr K-L Mah for collecting the Narenga porphyrocoma leaf samples. All sequences from this study have been deposited in EMBL/GenBank. Assemblies performed from third party data and all alignments and phylogenetic trees have been deposited in Dryad. 


\section{SUPPLEMENTARY MATERIALS}

All datasets from this study, including sequence assemblies from third party SRA datasets and optimized alignments have been deposited in the Dryad repository: . Alignments and phylogenies have been deposited in TreeBase: TB2:S21154 and TB2:S21155. Sequence assemblies were deposited in EMBL/GenBank under the project identifiers: PRJEB17861 and PRJEB22229. Supplementary Appendices 1, 2 and 3 are available with the on-line version of the journal. 


\section{REFERENCES}

Bailey G., King G., Manighetti I. 2002. Tectonics, volcanism, landscape structure and human evolution in the African Rift. In: Bailey G, Charles R, Winder N, editors. Human ecodynamics: Proceedings of Association for Environmental Archaeology Conference 1998 held at the University of Newcastle upon Tyne. Pp. 31-46. Oxford: Oxbow.

Besse P., Mcintyre C.L., Berding N. 1997. Characterization of Erianthus sect. Ripidium and Saccharum germplasm (Andropogoneae-Saccharinae) using RFLP markers. Euphytica 93:283-292.

Besse P., Taylor G., Carroll B., Berding N., Burner D., McIntyre C.L. 1998. Assessing genetic diversity in a sugarcane germplasm collection using an automated AFLP analysis. Genetica 104:143-153.

Böhringer S., Gödde R., Böhringer D., Schulte T., Epplen J.T. 2002. A software package for drawing ideograms automatically. Online J Bioinformatics. 1:51-59.

Burner D.M., Webster R.D. 1994. Cytological studies on North American species of Saccharum (Poaceae: Andropogoneae). SIDA, Contrib. Bot. 16:233-244.

Cheavegatti-Gianotto A., de Abreu H.M., Arruda P., Bespalhok Filho J.C., Burnquist W.L., Creste S., di Ciero L., Ferro J.A., de Oliveira Figueira A.V., de Sousa Filgueiras T., de Fátima Grossi-de-Sá M. 2011. Sugarcane (Saccharum X officinarum): a reference study for the regulation of genetically modified cultivars in Brazil. Trop. Plant Biology. 4:6289.

Chramiec-Głąbik A., Grabowska-Joachimiak A., Sliwinska E., Legutko J., Kula A. 2012. Cytogenetic analysis of Miscanthus $\times$ giganteus and its parent forms. Caryologia. 65:234-242. 
Clayton W.D. 1972. The awned genera of Andropogoneae. Studies in the Gramineae: XXXI.

Kew Bull. 27:457-474.

Clayton W.D.,, Vorontsova M.S. Harman K.T., Williamson H. 2006 onwards. GrassBase — The Online World Grass Flora. http://www.kew.org/data/grasses-db.html. [last accessed 01 June 2017; 08:05 GMT]

D’Hont A., Souza G.M., Menossi M., Vincentz M., van-Sluys M.A., Glaszmann J.C., Ulian E. 2008. Sugarcane: a major source of sweetness, alcohol, and bio-energy. In: Moore P.H, Ming R. editors. Plant genetics and genomics: crops and models. pp. 483-513 New York: Springer.

Divinagarcia N.S., Ramirez D.A. 1976. The Morphology and Cytology of Saccharum officinarum L. Indigenous to the Philippines. Philipp. J. Crop Sci. 1:1-25.

Drummond A.J., Ho S.Y.W., Phillips M.J., Rambaut A. 2006. Relaxed phylogenetics and dating with confidence. PLoS Biol. 4:e88.

Drummond A.J., Suchard M.A., Xie D., Rambaut A. 2012. Bayesian phylogenetics with BEAUti and the BEAST 1.7. Mol. Biol. Evol. 29:1969-1973.

Grassl C.O. 1972. Taxonomy of Saccharum relatives: Sclerostachya, Narenga, and Erianthus. Proceedings of 14th Congress, International Society of Sugar Cane Technologists (ISSCT). 240-248.

Grivet L., Daniels C., Glaszmann J.C., D’Hont A. 2004. A review of recent molecular genetics evidence for sugarcane evolution and domestication. Ethnobotany Res. Appl. 2004;2:9-17.

Ha S., Moore P.H., Heinz D., Kato S., Ohmido N., Fukui K. 1999. Quantitative chromosome map of the polyploid Saccharum spontaneum by multicolor fluorescence in situ 
hybridization and imaging methods. Plant Mol. Biol. 39:1165-1173.

Heinz D.J. editor. 2015. Sugarcane improvement through breeding (Vol. 11). pp. 237.

Amsterdam: Elsevier.

Hodkinson T.R., Chase M.W., Lledó M.D., Salamin N., Renvoize S.A. 2002. Phylogenetics of Miscanthus, Saccharum and related genera (Saccharinae, Andropogoneae, Poaceae) based on DNA sequences from ITS nuclear ribosomal DNA and plastid trnL intron and trnL-F intergenic spacers. J. Plant Research. 115:381-392.

Hodkinson T.R., Klaas M., Jones M.B., Prickett R. Barth, S. 2015. Miscanthus: a case study for the utilization of natural genetic variation. Plant Genet. Resour. 13:219-237.

Hoshino T., Davidse G. 1988. Chromosome numbers of grasses (Poaceae) from southern Africa. I. Ann. Missouri Bot. Gard. 75: 866-873

Huang X., Madan A. 1999. CAP3: A DNA sequence assembly program. Genome Res. 9:868877.

Jagathesan D., Sreenivasan, T.V. 1967. Cytogenetical Studies in Narenga porphyrocoma. Cytologia. 32:11-18.

Janaki-Ammal E.K. 1942. Intergeneric hybrids of Saccharum: IV. Saccharum-Narenga. J. Genet. 44:23-32.

Koren, S., Walenz, B.P., Berlin, K., Miller, J.R., Bergman, N.H. and Phillippy, A.M., 2017. Canu: scalable and accurate long-read assembly via adaptive k-mer weighting and repeat separation. Genome research, 27(5), pp.722-736. 
Kim C., Wang X., Lee T.H., Jakob K., Lee G.J. Paterson A.H. 2014. Comparative analysis of Miscanthus and Saccharum reveals a shared whole-genome duplication but different evolutionary fates. The Plant Cell. 26:2420-2429.

Lanfear R., Calcott B., Kainer D., Mayer C., Stamatakis A. 2014. Selecting optimal partitioning schemes for phylogenomic datasets. BMC Evol. Biol. 14:82.

Li H.W., Shang K.C., Hsiao Y.Y., Yang, P.C. 1959. Cytological studies of sugarcane and its relatives. Cytologia. 24:220-236.

Lloyd Evans D, Joshi SV. 2016. Complete chloroplast genomes of Saccharum spontaneum, Saccharum officinarum and Miscanthus floridulus (Panicoideae: Andropogoneae) reveal the plastid view on sugarcane origins. Systematics and Biodiversity. 14:548-571.

Lloyd Evans D, Joshi SV, Wang J. 2019a. Whole chloroplast genome and gene locus phylogenies reveal the taxonomic placement and relationship of Tripidium (Panicoideae: Andropogoneae) to sugarcane. BMC Evolutionary Biology, 19(1), pp.1-20.

Lloyd Evans D, Hlongwane TT, Joshi SV, Riaño Pachón DM. 2019b. The sugarcane mitochondrial genome: assembly, phylogenetics and transcriptomics. PeerJ. 7:e7558.

Lloyd Evans D. 2021. Combining protein-based transcriptome assembly, and efficient MinION long read sequencing for targeted transcript sequencing in orphan species. Validation on herbicide targets and low copy number genes in Gymnosperms, Juncaceae and Pteridophyta. bioRxiv. Doi: 10.11012020.10.24.353441.

Molina A.M. 1981. El género Erianthus (Gramineae) en la Argentina y países limítrofes. Darwiniana. 23:559-585.

Mukherjee S.K. 1958. Revision of the genus Erianthus Michx. (Gramineae). Lloydia. 21:157188. 
Nair N.V., Selvi A., Sreenivasan T.V., Pushpalatha K.N., Mary S. 2005. Molecular diversity among Saccharum, Erianthus, Sorghum, Zea and their hybrids. Sugar Tech. 7:55-59.

Nylander J.A., Wilgenbusch J.C., Warren D.L., Swofford D.L. 2008. AWTY (are we there yet?): a system for graphical exploration of MCMC convergence in Bayesian phylogenetics. Bioinformatics. 24:581-583.

Price H.J., Dillon S.L., Hodnett G., Rooney W.L., Ross L., Johnston, J.S. 2005. Genome evolution in the genus Sorghum (Poaceae). Ann. Bot. 95:219-227.

Rambaut A., Suchard M.A., Xie D., Drummond A.J.. 2013. Tracer, Version 1.5. Available at: tree.bio.ed.ac.uk/software/tracer/.

Reddy B.V., Ramesh S., Kumar A.A., Wani S.P., Ortiz R., Ceballos H. and Sreedevi T.K., 2008. Bio-fuel crops research for energy security and rural development in developing countries. Bioenergy Res. 1:248-258.

Rice P., Longden I., Bleasby A. 2000. EMBOSS: The European Molecular Biology Open Software Suite. Trends Genet. 16:276-277

Ronquist F., Huelsenbeck J.P. 2003. MrBayes 3: Bayesian phylogenetic inference under mixed models. Bioinformatics. 19:1572-1574.

Selvi A.N., Nair V., Noyer J.L., Singh N.K., Balasundaram N., Bansal K.C., Koundal K.R., Mohapatra T. 2006. AFLP analysis of the phenetic organization and genetic diversity in the sugarcane complex, Saccharum and Erianthus. Genet. Resour. Crop Evol. 53:831842.

Shi C., Wang S., Xia E.H., Jiang J.J., Zeng F.C., Gao, L.Z. 2016. Full transcription of the chloroplast genome in photosynthetic eukaryotes. Sci. Rep. 6:30135. 
Shrivastava A.K., Srivastava S. 2016. Diversity of the germplasm of Saccharum species and related genera available for use in directed breeding programmes for sugarcane improvement. Current Sci. 111:475-482.

Šmarda P., Bureš P. 2012. The variation of base composition in plant genomes. In: Plant Genome Diversity Volume 1. pp 209-235. Vienna: Springer.

Smith D.R. 2012. Updating our view of organelle genome nucleotide landscape. Front. Genet. 3:175.

Stamatakis A. 2006. RAxML-VI-HPC: Maximum likelihood-based phylogenetic analyses with thousands of taxa and mixed models. Bioinformatics. 22:2688-2690.

Strydom A., Spies J.J., Van Wyk S.M.C. 2000. Poaceae: Chromosome Studies On African Plants. 14. Panicoideae. Bothalia. 39:201-214.

Sun, Y., Cheng S.Q., Liang, G.H. 1994. Induction of autotetraploid plants of Sorghum versicolor. Cytologia, 59(1), pp.109-114.

Turudić, A., Liber, Z., Grdiša, M., Jakše, J., Varga, F. and Šatović, Z., 2021. Towards the Well-Tempered Chloroplast DNA Sequences. Plants, 10(7), p.1360.

Valdés B., Scholz H. 2006. The Euro+Med treatment of Gramineae: a generic synopsis and some new names. Willdenowia. 36: 657-669.

Walker, J.F., Jansen, R.K., Zanis, M.J. and Emery, N.C., 2015. Sources of inversion variation in the small single copy (SSC) region of chloroplast genomes.

Watson L., Dallwitz M.J. 1992. The grass genera of the world. Walingford, UK: C.A.B. International.

Welker CA, McKain MR, Vorontsova MS, Peichoto MC, Kellogg EA. 2019. Plastome 

made available under aCC-BY-NC-ND 4.0 International license.

phylogenomics of sugarcane and relatives confirms the segregation of the genus

Tripidium (Poaceae: Andropogoneae). Taxon, 68(2), pp.246-267.

Wick, R.R., Judd, L.M., Gorrie, C.L. and Holt, K.E., 2017. Unicycler: resolving bacterial genome assemblies from short and long sequencing reads. PLoS computational biology, 13(6), p.e1005595.

Zimov S.A., Zimov N.S., Tikhonov A.N., Chapin F.S. 2012. Mammoth steppe: A highproductivity phenomenon. Quat. Sci. Rev. 57: 26-45.

doi:10.1016/j.quascirev.2012.10.005 


\section{Figure Legends}

\section{Figure 1}

Schematic images for three complete chloroplast assemblies. Shown are three schematic drawings for the three chloroplast genomes assembled and annotated in the present study. Top left is the chloroplast of Miscanthidium capense, assembled from chloroplast PCR fragments. Top right is the chloroplast of Miscanthidium junceum, assembled from whole genome sort read data. Bottom is the chloroplast of Narenga porphyrocoma, assembled from transcriptomic data. Protein coding genes are shown on the outer track, with forward strand genes on the outside and reverse strand genes on the inside. The inner track shows the extent of the large single copy region (LSC), small single copy region (SSC) and the two inverted repeats (IRA and IRB). Images were drawn with GenomeVx prior to finishing with Adobe Illustrator. 
Figure 2

Whole Plastid Phylogram of Saccharum and Related Genera. Phylogram, representing the most likely topology from two independent runs of RAxML comparing whole chloroplast alignments of five Tripidium species along with the newly-assembled plastomes of Miscanthidium junceum, Miscanthidium capense and Narenga porphyrocoma with 31 representative members of the Andropogoneae. Arundinella deppeana is used as the outgroup. The two slashes (//) indicate that the long branch linking the outgroup to the remainder of the tree has been reduced by $50 \%$ so that internal relationships can be more clearly seen. Numbers next to nodes represent Maximum Parsimony bootstrap confidence/Bayesian inference where */* represents 100/1. The scale bar at the base of the phylogeny represents the expected number of substitutions per site. Images were drawn with FigTree prior to finishing with Adobe Illustrator. Currently accepted members of the Saccharinae are represented by a double dagger ( $\ddagger$ ) and currently accepted members of the Sorghinae are represented by an asterisk $(*)$ 
Figure 3

Chronogram for Andropogoneae divergence, focussing on the Saccharinae. The chronogram is based on whole plastid alignments showing the evolutionary distances (in millions of years) between the species and accessions analysed in this study. Numbers to the left of nodes show the age of the node in millions of years ago (Ma). Node bars give the 95\% highest posterior density (HPD) for the node age. The scale at the bottom gives millions of years before present in 2.5 million year increments. Arundinella deppeana is employed as the outgroup. Images were drawn with FigTree prior to finishing with Adobe Illustrator.

Figure 4

Phylogram based on five low copy number gene regions. A phylogram of Andropogoneae species, focussing on the core Saccharinae. Numbers next to nodes represent bootstrap confidence/Bayesian inference where '-’ represents confidences below the cutoff threshold ( $60 \%$ for MP and 0.7 for BI). The scale bar at the base of the phylogeny represents the expected number of substitutions per site. Divergent A and B genomes for Erianthus, Miscanthidium, Miscanthus and Narenga are shown by brackets. The phylogram was rooted on two Arthraxon accessions. 


\section{Figure 5}

Schematic ideograms for members of the core Saccharinae. Ideograms were generated from previously published chromosomal analyses. P and Q arms were measured with icy and rendered with coloredChromosomes. Chromosomes are aligned at the centromere and the minimum complement (n) only is shown. Species are ranked in order of evolutionary divergence.

Figure 6

Schematic images for two chloroplast isoforms of Narenga porphyrocoma. Shown are schematic drawings for the two chloroplast genomes isoforms of Narenga porphyrocoma annotated in the present study. Left (A) is the canonical form with the SSC in forward orientation and right (B) is the form with the SSC inverted. The inner track shows the extent of the large single copy region (LSC), small single copy region (SSC) and the two inverted repeats (IRA and IRB). Images were drawn with GenomeVx prior to finishing with Adobe Illustrator. 

made available under aCC-BY-NC-ND 4.0 International license.

\section{Figure 7}

Schematic of chromosome number evolution in the Saccharinae. Shown is a schematic dendrogram representing a possible route of chromosomal evolution within the core Saccharinae, attempting to explain why different base chromosomal counts are observed within different genera within the subtribe. Numbers at nodes give starting chromosome counts before divergence, numbers at the tips give the species level chromosome counts. 
bioRxiv preprint doi: https://doi.org/10.1101/2022.01 04.474895; this version posted January 7, 2022. The copyright holder for this preprint (which was not certified by peer review) is the author/funder, who has granted bioRxiv a license to display the preprint in perpetuity. It is made available under aCC-BY-NC-ND 4.0 International license.

Figures

Figure 1

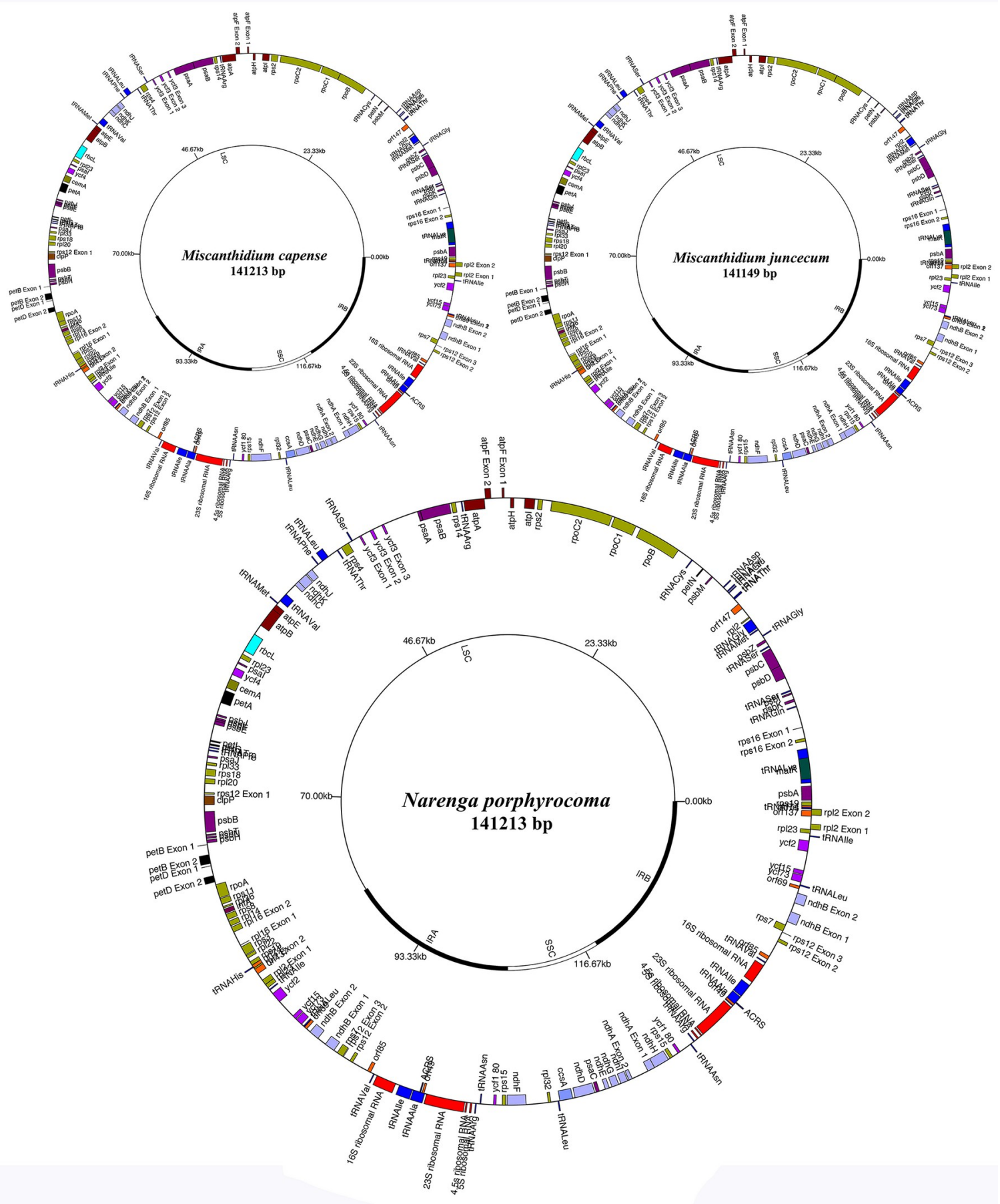


Figure 2

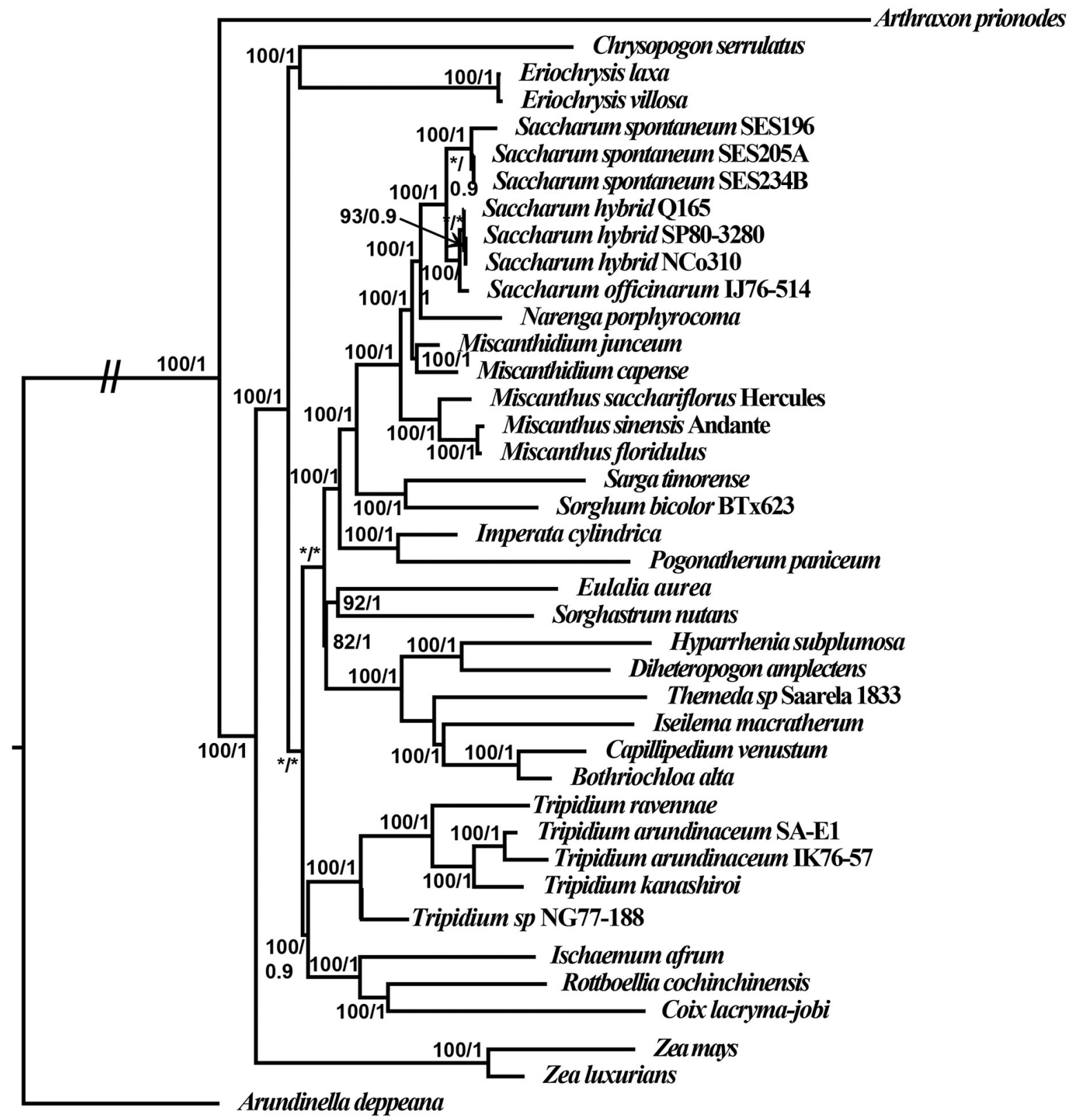

0.002 
bioRxiv preprint doi: https://doi.org/10.1101/2022.01.04.474895; this version posted January 7, 2022. The copyright holder for this preprint (which was not certified by peer review) is the author/funder, who has granted bioRxiv a license to display the preprint in perpetuity. It is made available under aCC-BY-NC-ND 4.0 International license.

Figure 3

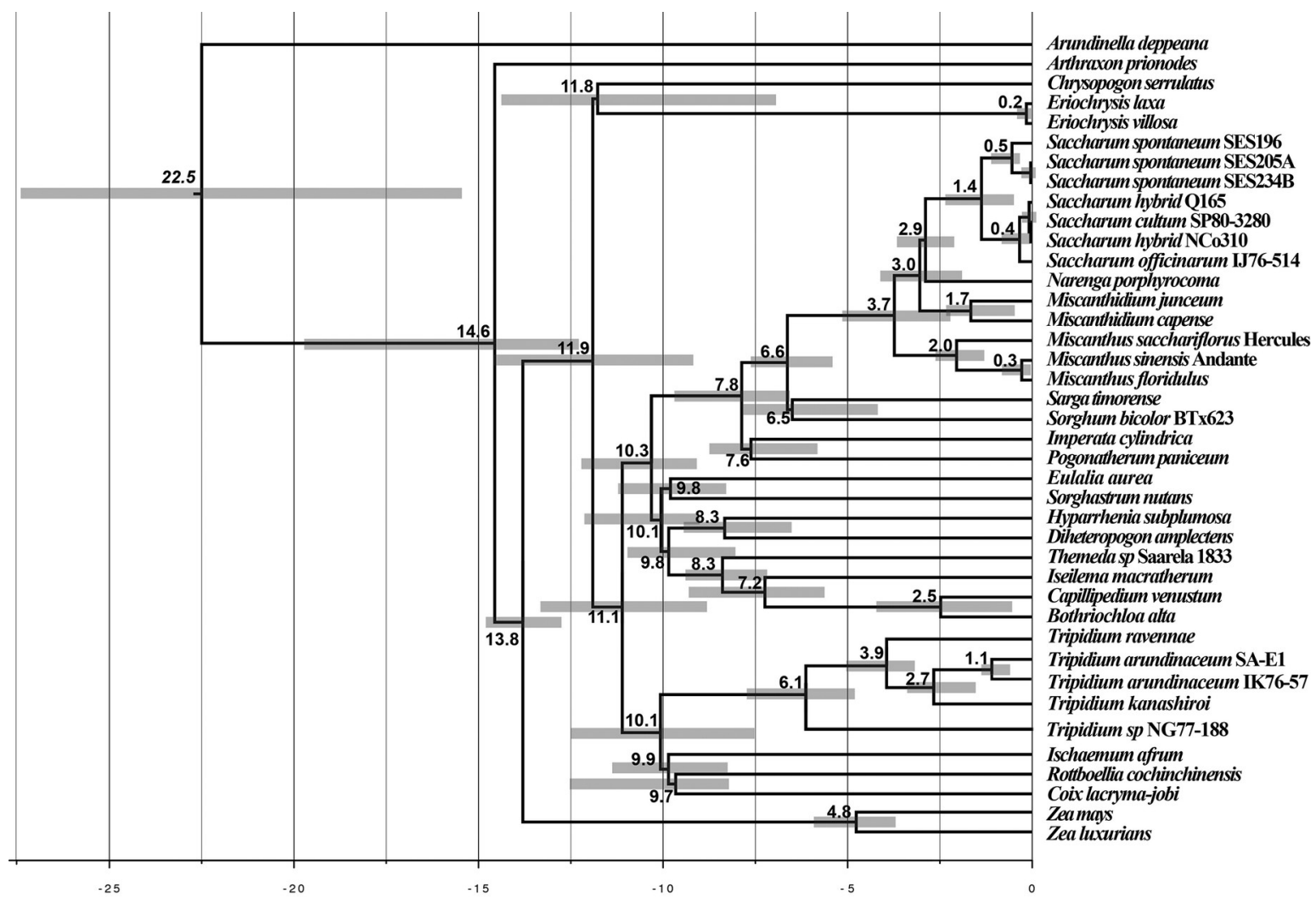


bioRxiv preprint doi: https://doi.org/10.1101/2022.01.04.474895; this version posted January 7, 2022. The copyright holder for this preprint (which was not certified by peer review) is the author/funder, who has granted bioRxiv a license to display the preprint in perpetuity. It is made available under aCC-BY-NC-ND 4.0 International license.

Figure 4

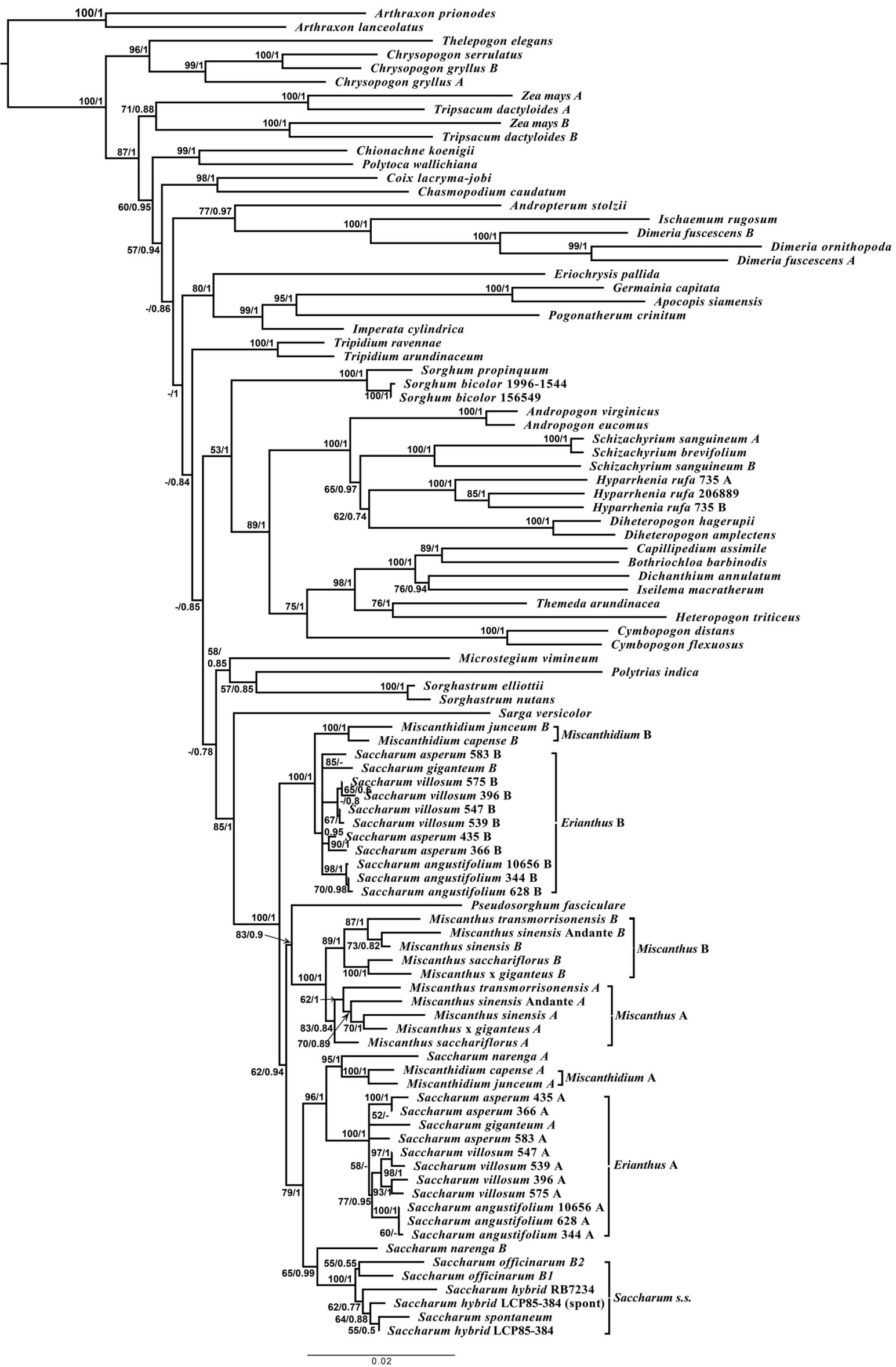


Figure 5

Sarga versicolor

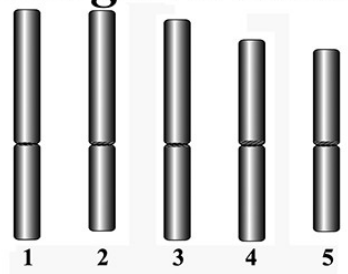

Miscanthidium capense

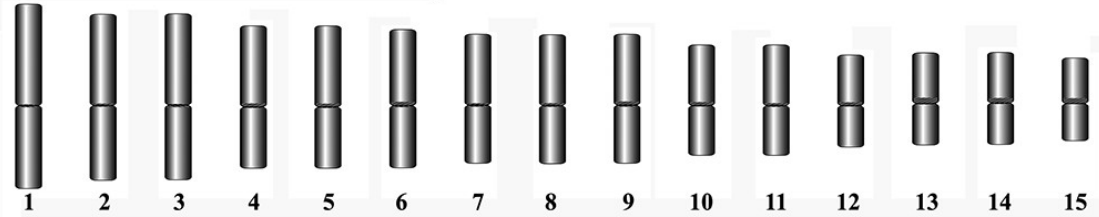

Erianthus giganteus

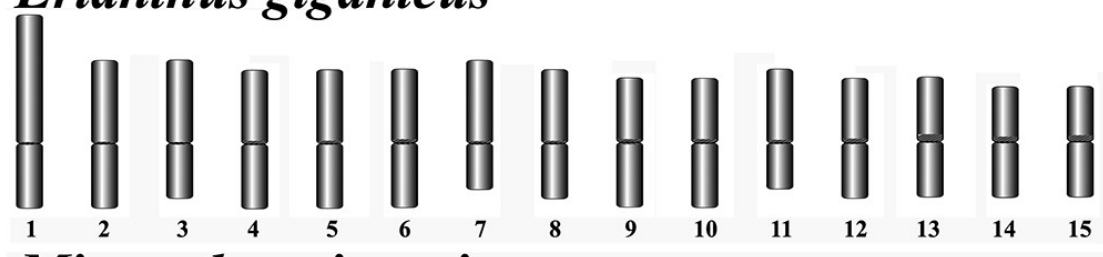

Miscanthus sinensis

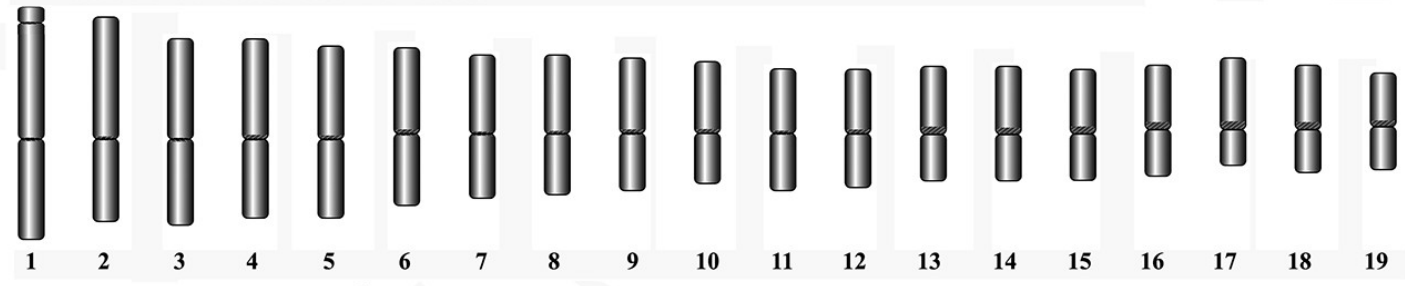

Narenga porphyrocoma

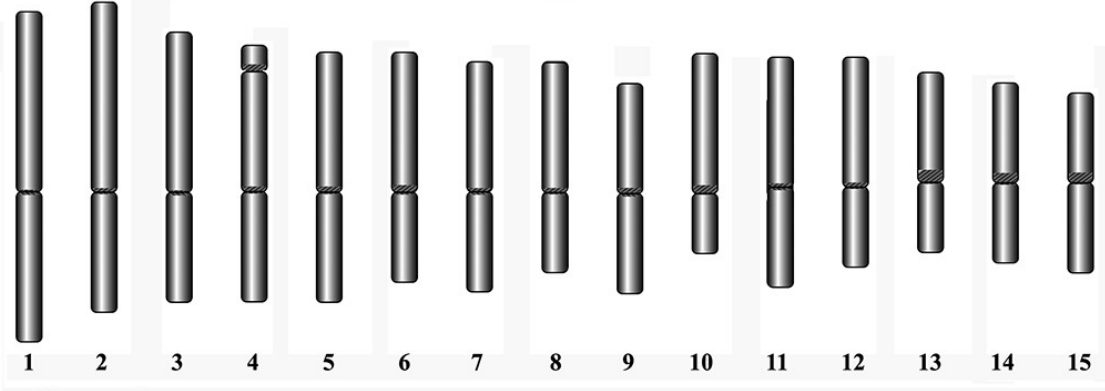

Saccharum spontaneum

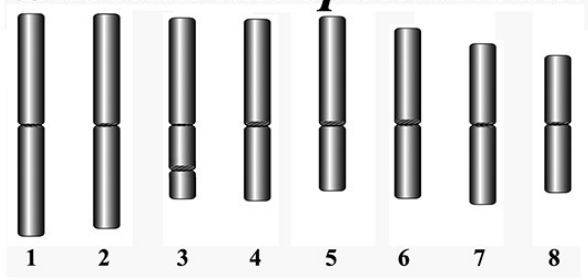

Saccharum officinarum

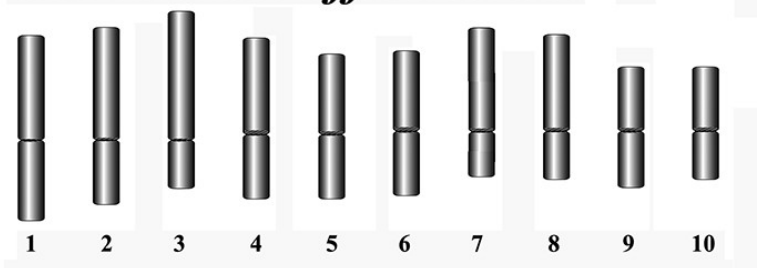

$5 \mu \mathrm{m}$ 
Figure 6
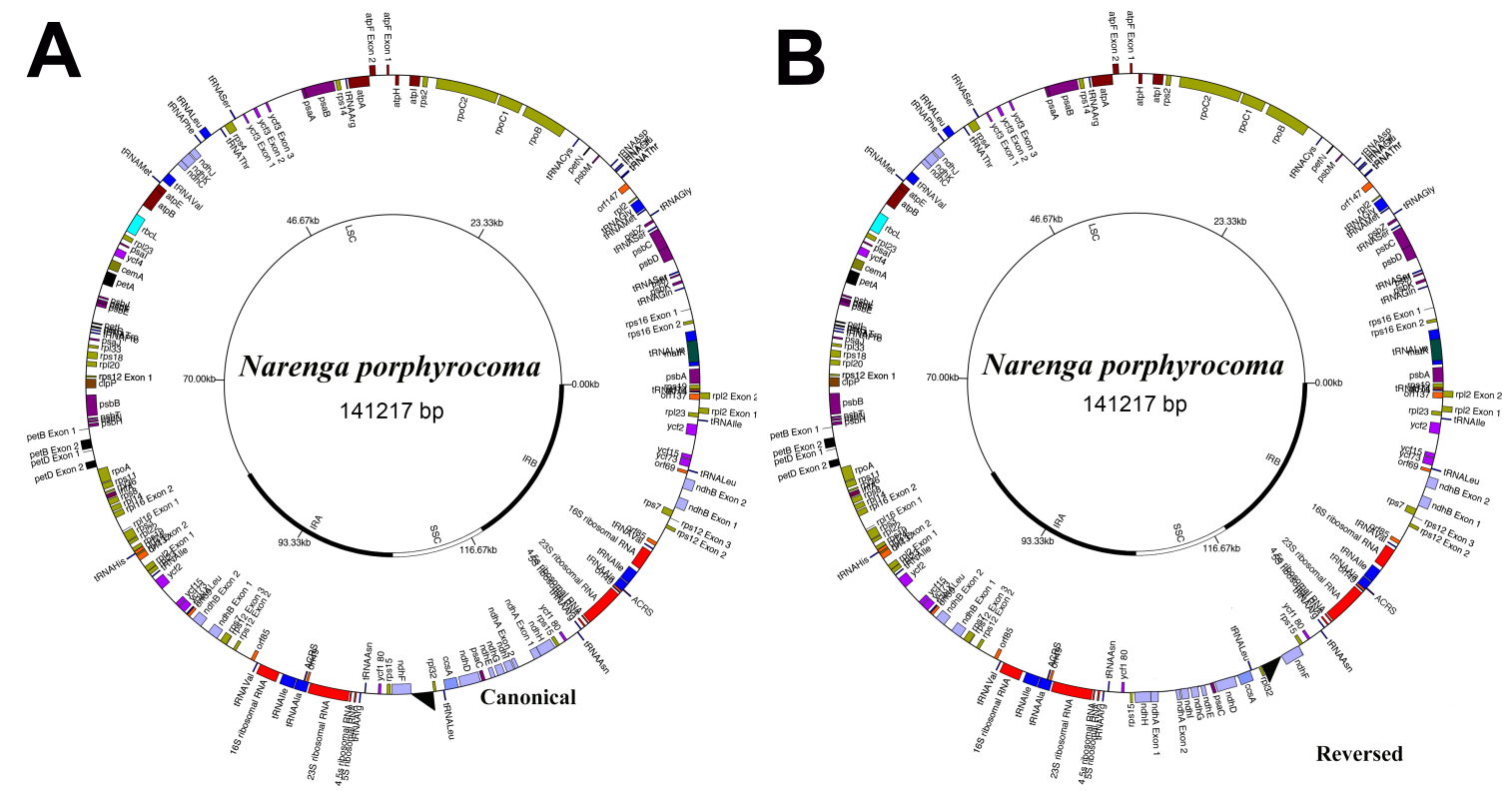
Figure 7

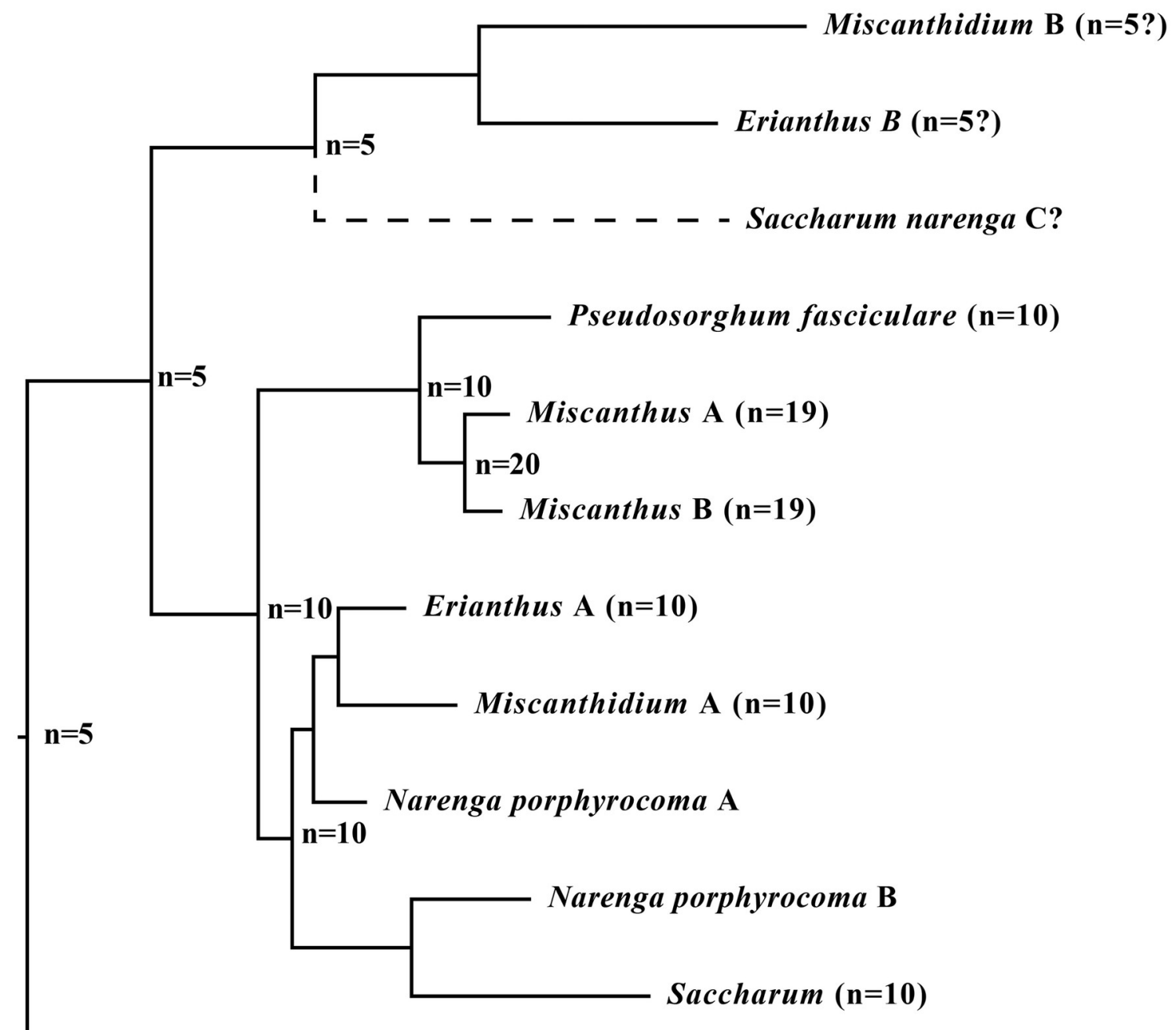

$\operatorname{Sarga}(\mathbf{n}=5)$ 